\title{
Analysis on Pragmatic Failures of Chinese Learners in Cross-Cultural Communication
}

\author{
Ge Liu \\ Department of foreign language teaching and research, Bohai University, Jinzhou, Liaoning 121003, China \\ Email:lg781115@163.com
}

\begin{abstract}
The basic aim of English teaching in college is making English majors successfully communicate with foreigners in English. Pragmatic competence directly reflects the appropriateness of flexible use of English for college English majors in cross-cultural communication. However, many studies show that pragmatic competence of college English majors in China is poor in cross-cultural communication. Moreover, pragmatic failures are one of the important reasons for the failure of cross-cultural communication. This paper systematically interprets the fundamental theory and specific forms of pragmatic failures from the perspective of cross-cultural communication. Main reasons of pragmatic failures are analyzed to improve the quality of English teaching and intercultural communication ability of college English majors in China.

Keywords: pragmatic competence, pragmatic failure, intercultural communication, English teaching strategies, college English majors
\end{abstract}

\section{INTRODUCTION}

Pragmatic competence refers to both knowledge of the linguistic forms of realizing particular illocution, and knowledge of using linguistic forms appropriately in certain social contexts. It directly reflects the appropriateness of flexible use of English for college students. Pragmatic failures beings unnecessary troubles and misunderstandings for cross-cultural communication have been one of the important reasons for the failure of intercultural communication in modern society [1]. English has been an international language for trade and education in the global context. The role of English, especially communicative competence in English, which refers to both the knowledge of language and the ability to use that knowledge in social interactions, has become more and more important in the daily life of people in China[2-3]. Due to the differences in cultural background, values and religious beliefs between the two sides of communication, college English majors often tend to misunderstand the use of English, which leads to the failure of international communication and even conflicts. Therefore, the study on pragmatic failures has already been one of the research hotspots in the field of English usages [4-5]. However, many studies show that pragmatic competence of college English majors in China is poor in cross-cultural communication. From the perspective of cross-cultural communication, this paper systematically interprets the basic theory and specific forms of pragmatic failure. Main causes of pragmatic failure of college English majors in China are analyzed to improve the quality of English teaching and intercultural communication ability of college English majors. The research results may be helpful to cultivation of pragmatic competence of college English majors in cross-cultural communication.

\section{FUNDAMENTAL THEORY OF PRAGMATIC FAILURE IN CROSS- CULTURAL COMMUNICATION}

The concept of pragmatic failures was firstly put forward by Jenny Thomas in the 1980s [6]. According to Thomas, pragmatic failure refers to the failure of people to achieve perfect communicative effect in language communication. In other words, the listener perceives the intentions of speakers are different from these of the speakers are trying to express [6]. Deborah Tannen believed that the study of intercultural speech communication is very important to study and apply linguistic theory. He also illustrated how the speaker could express his own meaning with words by means of discussion and examples, and illustrates various directions of speech communication due to different cultures. John Gumperz is the founder of interactive sociolinguistics. He believes that the study of intercultural communication errors is mainly reflected in the study of discourse strategies. Both sides of communication need to reason according to the background knowledge of specific occasions, interpersonal relationship knowledge and the knowledge of interaction purpose, and obtain indirect information to make the conversation go smoothly. He Ziran believed that "pragmatics does not refer to the mistakes of language use in the general choice of words and sentences, but to the mistakes of inappropriate speech, or improper way of speech and expression, which lead to the failure of communication to achieve the expected results." [7] Qian Guanlian defines pragmatic failure as: "the speaker uses the sentence with correct symbolic relationship in verbal communication, but unconsciously 
violates the interpersonal norms and social conventions, or does not conform to the time and space, and does not look at the object" [8]. This kind of error is called pragmatic failure [8-9]. However, it should be pointed out that pragmatic failure is not a problem of one party, and the responsibility is not entirely on one side. When the listeners fail to understand the intention according to the expectation of the speakers, both parties are responsible for pragmatic failure [10]. The speaker fails to accurately estimate the degree of knowledge and information shared by the hearer and himself, while the hearer thinks the understands the discourse according to his own cultural habitual way, does not consider that the two sides come from different cultural circles and have certain cultural differences, these related issues need to be further studied.

\section{MAIN FORMS OF PRAGMATIC FAILURES IN CROSS-CULTURAL COMMUNICATION}

\subsection{Linguistic Failure of Language}

Based on Leech's linguistic framework, Thomas divides pragmatic failure into two categories: linguistic failure and social pragmatic failure. Due to the lack of the ability to correctly understand or properly use the language forms and functions shared by both sides of the conversation at that time to express the intended meaning, Chinese students habitually bring their mother tongues into the target language of English, and uses the target language of English expression incorrectly, which violates the habit of English expression. It mainly includes: phonetic pragmatic failure, lexical pragmatic failure, grammatical pragmatic failure and discourse pragmatic failure [11]. For example, when an American student visited his Chinese teacher, the teacher wanted to invite him to have dinner and said, "Would you like to come to my home for dinner next Saturday?" The student readily accepted the invitation and agreed on a specific meeting time. After two days, the students came, but the teacher was very surprised. Because there was no preparation in advance, the scene was extremely embarrassing, so he said: "the day before yesterday, I said next Saturday, please. You see, I'm not ready for anything today ...". The student said, "The day before yesterday, you said you would invite me to have dinner next Saturday. Isn't that today?" This misunderstanding between China and the West resulted from different understandings of "next Saturday". The difference of the expressions ("last week", "this week" and "next week") between English and Chinese is that the reference point of observation time is different in the actual teaching process. The Chinese speaking time is next Saturday, that is, the speaking week is the reference point, that is, the next Saturday after this week. English, on the other hand, refers to the Saturday that will come after Wednesday. So there was the misunderstanding mentioned above.

\subsection{Social Pragmatic Failure}

As we all know, as a social phenomenon, language has the function of historical cultures or "storage" (that is, the function of accumulating and storing cultural and historical experience), its communicative function is most essential, however. Language communication is a process of information exchange. It is closely related to culture. The use of English cannot exist independently of culture. From the book on language written by Edward Sapir, an American linguist, it is realized that "the communicative function of language is closely related to the storage function of language and is mutually conditional" [9]. In different social situations, the speakers can't take into account cultural background, living habits and language characteristics of the communicators, which easily result in social pragmatic failure. Due to the lack or neglect of social and cultural background differences, the wrong choice of language expression forms includes: request pragmatic failure, compliment pragmatic failure, politeness pragmatic failure, apology pragmatic failure and greeting pragmatic failure [12]. For example, a British female teacher praised the calligraphy of Chinese female students as "Oh, what's beautiful writing!", but the Chinese students said: "no, no, not at all. You're joking." Although the students follow the principle of modesty, her answer may suggest that the speaker is ignorant of calligraphy works and lacks aesthetics and appreciation. As a result, English female teachers are very angry. It is not surprising that Chinese people are used to expressing modesty in the way of "denial" or "self abasement".

\section{MAIN REASONS FOR PRAGMATIC FAILURE IN CROSS-CULTURAL COMMUNICATION}

\subsection{Different Cultural Backgrounds Resulting in Pragmatic Failure}

In the process of language communication between China and the west, language and culture are inseparable. Due to the differences between Chinese and English cultures in historical background and cultural tradition, people have already formed a set of daily communication with each other according to their own speaking mode. It is even natural to being our own language habits and ways of speaking into the dialogue, leaving a bad impression on each other, which leads to the failure of communication. Taking kinship terms as an example, kinship terms such as "Grandpa, grandma, uncle, aunt" have been introduced to social occasions, even widely used by strangers. Gina, an American, was invited to visit a kindergarden in China. The children called her "aunt". She was confused and thought that she was not the sun of these children. How could she be called that? In conclusion, Chinese and western languages have differences in different fields due to their different cultures and backgrounds. This required 
the Chinese college students to pay attention to understanding the back background and cultural tradition of English, and to make dynamic adjustments in the process of communication.

\subsection{Different Folk Customs Resulting in Pragmatic Failure}

The mistakes caused by the speaker's inability to use the language appropriately in different communication situations and according to the language habits and characteristics of the language communicators from different cultural backgrounds. This phenomenon often occurs in cross-cultural communication errors caused by the ignorance of each other's folk customs and life style, and even leads to violent conflicts. For example: when they meet, Chinese people greet each other. They are used to asking if you have eaten (Have you had your meal?), or where would you like to go? Where are you going? (How are you?) or Hello. If you ask British and Americans with greetings from Chinese people, they will have a misunderstanding that you want to invite them to have dinner or interfere in other people's private affairs. British and American greeting usually starts from the weather and then exchanges.

\subsection{Different Values Resulting in Pragmatic Failure}

Every culture and every society has different values. Due to the different customs between China and the west, there are also great differences between values. They are individualism and collectivism, interaction and independence, intimacy and privacy. Westerners believe in Christianity, and believe that individualism, individual struggle, independence and independence are the mainstream cultural values. Americans are most concerned about individualism and self-interest. The core of their values is individual independence. This kind of selfawareness is manifested in privacy in personal life. The strong demand of Americans for personal privacy makes the constitution of the United States List it as an inviolable right of every citizen. In Chinese cultural values, the group value is higher than the individual value, and the individual has always been regarded as a part of the society, emphasizing the reasonability of the individual to the society and others, and emphasizing the mutual help and care between people. If the college English student in China reminds Americans: "It's cold outside, wear more", they will think how old I am, and don't need you remind them, and even they will feel insulted. Therefore, if college students are not sensitive to the cultural value differences between the two sides of communication and hold an exclusive attitude towards cultural differences, it is easy to have communication conflicts. As a result, they need to agree with each other's values, and make dynamic adjustments in the process of communication.

\subsection{Different Negative Transfers of Mother Tongues Resulting in Pragmatic Failure}

It has formed its own unique native language expression mode due to the long-term influence of our traditional cultures. Although second language learners have received foreign language education, they have misused the language rules of their mother tongue to the target language of English, that is to say, negative transfer occurs, which interferes with normal communication. For example, "My English teacher has peaches and plums all over the country". In Chinese, teachers are often compared to hardworking gardeners and students to peaches and plums in the garden. However, it's not appropriate to use this metaphor in English, because there is no habit of using "peach" and "plum" to express the concept of "student". This kind of copying directly affects the exchanges between the two sides and make foreigners at a loss.

\subsection{Different Thinking Styles Resulting in Pragmatic Failure}

The way of thinking is a bridge to communicate culture and language, while the different cultural backgrounds between China and the West hinder the communication between different cultures. For example, there are differences between China and the West in expressing concern for patients. If you hear that a friend's family member is ill, Chinese will often use a conciliatory tone to persuade the friend: "Don't worry, it will be OK!" I'm sorry to hear that! Americans are more interested in the independence of individuals, and being taken care of is often seen as the weak. When giving advice or suggestions to the other party, you cannot make the other party think that you belittle his ability. American response to the above is usually ("Take care of yourself! I hope you'll be better soon.")Don't have to teach people how to do it. Chinese people show concern by making suggestions, and in the tone of brothers, sisters, parents and relatives, or in the tone of the past, this is not feasible for Americans. Therefore, different thinking styles could also result in pragmatic failure in cross-cultural communication.

\subsection{Lack of Common Union Information Resulting in Pragmatic Failure}

Chinese and English belong to two types of languages, which are quite different. The lack of language knowledge and the cultural differences related to languages also result in pragmatic failure. For example, "the horse successfully crossed the hurdle", which can be automatically segmented into "horse / success / crossing / crossing / that road / hurdle" or "horse success" can be looked on as a person's name, "horse success / crossing / crossing / that road / hurdle". Different from English, the first letter of proper noun must be capitalized, and the English corresponding to "Ma Cheng gong" is "Ma Cheng gong or 
foreign countries Theory Horizon. 491(2014) 59. DOI: https://10.13221/j.cnki.lljj.2014.07.018

[4] N. Al-Ghandi, N. Almansoob, Y. Alrefase, Pragmatic failure in the realization of the speech act of responding to compliments among Yemeni EFL Undergraduates. Language, Linguistics, Literature, December 30, 2019.

DOI: http://dx.doi.org/10.2139/ssrn.3511561

English has developed into a lingua franca in such domains as politics, economy, society, culture, and education today. Knowledge of the English language has indeed acted as a powerful tool for development and advancement throughout the world. Pragmatic competence directly reflects the appropriateness of flexible use of English for college English majors. Meanwhile, pragmatic failure often caused by the failure to grasp the connotation of discourse culture in a timely manner in the process of cross-cultural communication is one of the important reasons for the failure of Chinese students in intercultural communication. However, many studies show that pragmatic competence of college English majors in China is poor in cross-cultural communication. From the perspective of cross-cultural communication, this paper systematically interprets the basic theory and specific forms of pragmatic failure of English. Main causes of pragmatic failure of college English majors in China are analyzed to improve the quality of English teaching and intercultural communication ability of college English majors. As a result, Chinese learners must avoid pragmatic failure to communicate efficiently. It could help to reduce or even inhibit the pragmatic failures in cross-cultural communication in the process of teaching and training of English.

\section{ACKNOWLEDGMENT}

This work was supported by Liaoning Province Education Science Planning Project in China (Project No: JG17DB).

\section{REFERENCES}

[1] Z-B. Guan, Pragmatic failures from the perspective of cross-cultural communication, Journal of Huangshi Institute of Technology (Humanities and Social Sciences, 1(2007) 101.

[2] Z. Hu, Study on developing Chinese college EFL learners' pragmatic competence in relation to language proficiency and overseas experience, Journal of Language Teaching and Research, 5(2014)391-398

[3] T. Ma, Protect the basic status of Chinese language in the cultural communication between china and
[5] N. Ghazzoul, Linguistiv and pragmatic failure of Arab learners in direct polite requests and invitations: A Cross-cultural Study. Theory and Practice in Language Studies, 9(2019)223

[6] J. Thomas, Cross-cultural Pragmatic Failure. Applied Linguaistics, 1983

[7] Z-R He. An introduction to pragmatics. Changsha: Human Education Press, 2000

[8] G-L. Qian, Language: the last home of mankind. Beijing: Commercial Press, 2005

[9] Sapir. Introduction to speech studies in linguistic theory. Beijing: Commercial Press, 1964:129.

[10] P. Cruz. Manuel, Understanding and overcoming pragmatic failure in intercultural communication: From focus on speakers to focus on hearers, International Review of Applied Linguistics in Language Teaching, 51(2013)23-54, DOI: https://doi.org/10.1515/iral-20130002

[11] X-R. Chen, M. Li, Pragmatic Failures Reconsidered in the Context of English as a Lingua Franca, Foreign Languages and Their Teaching, 2 (2015)7-12

[12]W-F. Hua, On pragmatic failure of English language learners in intercultural communication. Journal of Shenzhen University (Humanities \& Social Sciences), 17, 2(2000):71-76 